\title{
Prospectiva e Democracia Participativa: Potencialidades e constrangimentos ${ }^{1}$
}

Margarida Perestrelo ${ }^{*}$

\begin{abstract}
$\mathrm{R}$ num processo de planeamento estratégico territorial e as regras de participação, de deliberação e de distribuição de poder que lhe estão associadas. Analisa-se a relação e o papel fundamental da prospectiva no planeamento estratégico participativo, a nível territorial. Defende-se que a prospectiva é uma reflexão à apreensão dos fenómenos estruturantes da realidade complexa e instável, que capacita os actores para formas de intervenção mais eficazes, seja antecipando seja inflectindo algumas das principais tendências de desenvolvimento. Tendo como ponto de partida a complexidade crescente da gestão do território, as transformações sociais e o clima de incerteza, considera-se o planeamento estratégico territorial e a abordagem prospectiva como duas faces da mesma moeda. As metodologias de prospectiva têm um papel fundamental não só ao nível do planeamento estratégico e participado, como ainda na construção de uma democracia participativa. Privilegia-se a importância da motivação para a participação no contexto da democracia participativa, não por uma questão ideológica, mas como uma exigência do próprio processo de planeamento: a efectivação do plano depende da implicação e contribuição voluntária dos actores bem como da mobilização dos recursos de que dispõem para concretizar a acção. Procura-se ainda analisar e discutir os diversos papéis dos protagonistas de um jogo estratégico de actores, a forma como os actores regulam as suas relações, as regras que estabelecem para enfrentarem, segundo as suas próprias lógicas, os conflitos em que estão envolvidos e as incoerências que engendram. Tendo em conta a importância da coesão interna, mobilização e implicação colectiva, dá-se uma atenção particular ao papel de dois actores cruciais em todo o processo: o actor/cliente e o investigador/ /cientista/analista.
\end{abstract}

Palavras-chave: Planeamento; Território; PNP○T.

\section{Introdução}

- presente artigo tem como objectivo reflectir sobre o papel dos actores sociais num processo de planeamento estratégico territorial e as regras de participação, de deliberação e de distribuição de poder que lhe estão associadas. Analisa-se a relação e o papel fundamental da prospectiva no planeamento estratégico participativo, a nível territorial. Defende-se que a prospectiva é uma reflexão à apreensão dos fenómenos estruturantes da realidade complexa e instável, que capacita os actores para formas de intervenção mais eficazes, seja antecipando seja inflectindo algumas das principais tendências de desenvolvimento. De facto, assiste-se hoje ao reconhecimento das potencialidades das metodologias de prospectiva ao nível do planeamento estratégico urbano e regional como processo interactivo de pensamento e acção que permite aumentar a capacidade

\footnotetext{
* Socióloga. Professor Auxiliar do Departamento de Métodos Quantitativos do ISCTE. Membro do Dinâmia e do GIESTA. Colaboradora do CET. Contacto: margarida.perestrelo@isct.pt

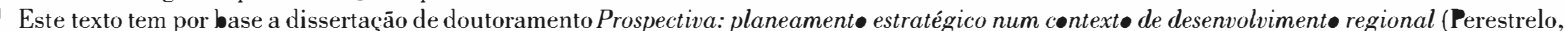
2005). É o resultado de um percurso, de um acumular de experiências académicas e profissionais, da participaçāo em diversos projectos de investigaçāo no Dinâmia e CET, da interdisciplinaridade e reflexāo colectiva intrínseca às metodologias de prospectiva.
} 
reflexiva dos actores sociais, dinamizar e apoiar a tomada de decisão e a acção colectiva.

Tendo como ponto de partida a complexidade crescente da gestão do território, as transformações sociais e o clima de incerteza, considera-se o planeamento estratégico territorial e a abordagem prospectiva como duas faces da mesma moeda. A prospectiva projecta o futuro no presente, com base no conhecimento dos actores do passado e do presente e é o resultado de aprendizagens que a reflexão colectiva e as múltiplas interacções promovem. O planeamento é assim um processo de aprendizagem colectiva, quer pelo aumento da capacidade reflexiva dos actores quer pelas mudanças induzidas, quer ainda pelo conteúdo e pelo processo de análise que desencadeia.

As metodologias de prospectiva, nomeadamente a Análise Estrutural e Análise da Estratégia de Actores $^{2}$ têm um papel fundamental não só ao nível do planeamento estratégico e participado, como ainda na construção de uma democracia participativa. Privilegia-se a importância da motivação para a participação no contexto da democracia participativa, não por uma questão ideológica, mas como uma exigência do próprio processo de planeamento: a efectivação do plano depende da implicação e contribuição voluntária dos actores bem como da mobilização dos recursos de que dispõem para concretizar a acção. É neste quadro que se afirmam as metodologias de prospectiva enquanto metodologias de investigação-acção, associadas ao processo de aprendizagem colectiva, de conhecimento e auto-reflexividade dos actores sociais, procurando provocar a mudança social.

Procura-se analisar e discutir os diversos papéis dos protagonistas de um jogo estratégico de actores, a forma como os actores regulam as suas relações, as regras que estabelecem para enfrentarem, segundo as suas próprias lógicas, os conflitos em que estão envolvidos e as incoerências que engendram. De que forma é possível implicar e mobilizar os actores sociais no processo de planeamento? Quais as fragilidades inerentes a um processo de planeamento estratégico participativo? Quais os pré-requisitos para o sucesso das metodologias de prospectiva territorial e o seu contributo para uma democracia participativa?
Num contexto de acção colectiva, a tomada de decisão está associada à incerteza e à antecipação, sendo a mudança social o resultado de uma miríade de decisões de actores concretos portadores de uma racionalidade limitada. A mudança é o resultado de um processo colectivo de interdependência estratégico entre actores, um processo de aprendizagem colectivo de novos modelos relacionais, de novas capacidades de acção colectiva. Tendo em conta a importância da coesão interna, mobilização e implicação colectiva, dá-se uma atenção particular ao papel de dois actores cruciais em todo o processo "o actor/cliente e o investigador/ /cientista/analista.

\section{A importância da estratégia de actores no planeamento}

A emergência de um pensamento voltado para a complexidade marca o surgimento, nos anos 70, de uma diversidade de teorias, que procuram ultrapassar as limitações encontradas no paradigma racionalista de planeamento, planeamento tradicional, e surge o planeamento estratégico. Contrariamente ao planeamento tradicional, considera-se que o planeamento é mais do que uma escolha técnica de meios para atingir fins predefinidos, ele envolve uma "decisão social". Parte do que Simon designa por racionalidade limitada (bounded rationality), isto é, uma racionalidade orientada não para a procura da solução óptima mas de uma solução satisfatória (escolha de um entre vários futuros possíveis, dependentes da estratégia dos actores). O que tem como implicação que a qualquer tomada de decisão, em contexto social, está associado um elevado grau de incerteza. O planeamento é entendido como um processo contínuo, dinâmico, sujeito a revisão permanente, centrado na tomada de decisões e na interacção entre os diversos actores.

Considera-se que o planeamento estratégico pressupõe uma visão prospectiva. Prospectiva esta entendida como uma "abordagem que produz conhecimentos para a acção", como uma pedagogia da mudança, num mundo em mutação, e aprendizagem de um pensamento complexo.

O planeamento estratégico tem como pressuposto a definição de opções construídas a partir do

${ }^{2}$ Para um maior aprofundamento ver Perestrelo (2005). 
interesse colectivo. Consequentemente, o plano deve ser uma referência para os seus intervenientes e destinatários: os actores sociais. Espera-se que um planeamento com estas premissas, se traduza numa mobilização e participação dos actores em todo o processo.

No entanto, há que ter presente que a qualquer processo de planeamento estratégico está subjacente a gestão do processo com duas características nem sempre reconciliáveis: pragmatismo e celeridade (Guerra, 2000b). Efectivamente, a celeridade que se exige na implementação de um plano nem sempre se coaduna com as formas de participação e implicação dos diversos actores sociais nesse mesmo processo, daí a procura de metodologias que respondam eficiente e eficazmente a este imperativo.

A metodologia prospectiva de análise estratégica de actores constitui um bom instrumento, não só como apoio à decisão, mas sobretudo como um meio de envolvimento e participação dos diferentes actores. No entanto, apesar do desenvolvimento deste tipo de metodologias, há ainda muitas lacunas nas formas de participação e envolvimento dos parceiros, não apenas pela morosidade dos processos, como pelas técnicas empregues para um envolvimento eficaz e produtivo.

Da identificação dos sistemas de relações complexas que se desenvolvem entre os actores e da análise das relações de forças e conflitualidades, destaca-se a diversidade e heterogeneidade existentes, tanto de actores, como de projectos e interesses, por vezes, contraditórios. Ora, é o reconhecimento desta variedade e heterogeneidade de actores intervenientes e projectos, que leva os actores públicos a procurar formas de negociação, compromissos de gestão do território, os quais passam pela análise estratégica dos actores, o que representa uma forma de regulação social e de governança.

Pode-se considerar que o resultado da acção colectiva é sempre um sistema de relações estabilizado devido a três factores: coordenação das actividades e das relações entre actores; distribuição de recursos relacionados com essas actividades; e estruturação (prevenção e resolução) dos conflitos (Guerra, 2002:56).

$\mathrm{O}$ facto de um actor possuir determinadas estratégias para o território, sendo como tal portador de racionalidades, não significa lucidez ou consciência. Daí a importância da análise das suas estratégias, assim como a clarificação das suas opções estratégicas. É precisamente o objecto de uma sociologia interaccionista, o de elucidar as formas de construção da acção colectiva, clarificar os papéis dos diferentes actores, perceber como se processam os conflitos e os consensos ao nível das relações de poder que fazem parte de uma dada realidade.

Se no planeamento estratégico se pressupõe como indispensável a participação e implicação dos actores em todo o processo, então a negociação é uma condição. Há regras e papéis diferenciados, consoante os vários actores protagonistas e implicados nesse processo. No planeamento urbano e regional, actores com interesses e objectivos específicos, como a administração pública, o poder local ou central, têm simultaneamente um papel de gestão do processo, competindo-lhes ainda garantir a igualdade de participação de todos os actores e não apenas de alguns. Pretende-se assim uma "democracia política" e não uma "democracia gestionária". No entanto, este duplo papel, de actor implicado no processo e de gestor desse mesmo processo, incorpora um conflito inerente (e latente) a qualquer processo de planeamento.

\section{Papel dos actores sociais no planeamento}

Ao considerar a análise estratégica, não apenas como apoio à decisão, mas como uma forma de gestão, mobilização e participação dos actores, deve-se questionar do papel diferenciado dos actores no processo de planeamento.

Estes distinguem-se consoante o seu poder e a maior ou menor capacidade de negociar, o que do ponto de vista do planeamento estratégico tem duas consequências: por um lado, os actores têm diferentes legitimidades e protagonismos no processo de planeamento; e, por outro, as suas estratégias definem-se conforme as possíveis alianças e vantagens daí retiradas. Qualquer negociação é realizada numa base desigual, há actores que "dominam" outros actores, seja do ponto de vista económico, cultural, simbólico, formal ou informal.

No entanto, para se construir um determinado plano, terá de haver uma coesão interna, um interesse colectivo, cujo sucesso é directamente 
proporcional à força do acordo e coesão conseguidos, daí a importância da constituição de "grupos estratégicos", que se vão formando ao longo do processo, por vezes centrados em objectivos estratégicos contraditórios, mas que se vão adaptando à mudança.

Tendo em conta o papel e peso que determinados actores têm no processo de planeamento regional e urbano, uma série de interrogações se colocam, nomeadamente: qual será o papel da administração pública/poder local e central neste processo? Qual o papel de actores com elevado poder na relação de forças, nomeadamente ao nível do planeamento urbano e territorial, como agentes fundiários e imobiliários? Qual a viabilidade de participação de actores com pouco ou nenhum poder neste jogo de relação de forças? Como se apela à participação e se representam no processo de planeamento populações excluídas? Qual o papel do actor/cliente na análise de estratégia de actores? Qual o papel do investigador/cientista/analista na análise de estratégia de actores?

\section{O papel do actor/cliente na estratégia de actores}

A inexistência de acordos e compromissos por parte dos protagonistas de um processo de planeamento será, a prazo, a falência do plano. Como tal, é uma prática por parte dos seus responsáveis, nomeadamente a nível do planeamento urbano e territorial, solicitar estudos para analisar as estratégias dos diferentes actores.

Entretanto, a entidade responsável pelo plano, com um papel fulcral em todo o processo de planeamento, é também um dos protagonistas deste jogo estratégico, pelo que se justifica a sua designação como actor/cliente. Esta dupla identidade, faz com que tenha uma posição pouco transparente e, em certa medida, um pouco "híbrida". Ou seja, é por um lado, cliente dos resultados da análise do jogo estratégico dos actores implicados no processo; e, por outro mediador e negociador; decisor; e, finalmente, actor deste processo!... ${ }^{3}$

Ao conceber a análise do jogo estratégico dos actores como uma das etapas fundamentais do pla- neamento estratégico, não apenas um instrumento de apoio à decisão por parte dos responsáveis pelo plano, mas sobretudo um meio de envolver e implicar os actores, deve-se interrogar e clarificar o papel do actor/cliente.

Será que não há uma certa promiscuidade no papel do actor/cliente? Efectivamente, o actor/cliente ao ter acesso, por vezes em exclusivo, a informação privilegiada, como as predisposições e estratégias dos diferentes actores, pode reduzir o seu grau de incerteza. No entanto, os outros actores protagonistas deste processo, têm apenas acesso a informação disponibilizada e controlada pelo actor/cliente e, por vezes, censurada (manipulada), o que poderá ter como consequência não uma clarificação e implicação dos restantes actores em todo o processo, mas um maior nível de incerteza quanto ao futuro do "seu" território!

É sob o disfarce de um planeamento estratégico participativo, que esta posição "híbrida" e promíscua do actor/cliente, pode resultar em manipulação e controlo social. A participação pelos seus efeitos mobilizadores e integradores, donde reguladores, pode contribuir para uma certa forma de controlo social.

Se é certo que, como defendem Crozier e Friedberg (1977), o poder de um actor é função da amplitude da zona de incerteza, ou seja é a imprevisibilidade do seu comportamento que lhe permite controlar os outros actores, no Planeamento Estratégico Urbano e Territorial, onde se apela à mobilização, participação e implicação de todos os actores, esta estratégia de actuação, resulta na total descredibilização deste processo.

“O poder de um indivíduo ou de um grupo, ou seja de um actor social, está em função da amplitude da zona de incerteza que a imprevisibilidade do seu próprio comportamento lhe permite controlar face aos seus parceiros. (...) a estratégia de cada um dos parceiros/adversários orientar-se-á, naturalmente, para a manipulação da previsibilidade do seu próprio comportamento e do outro, (...) modificando em seu favor as condições estruturais e as regras que regem as suas interacções com o outro." (Crozier e Friedberg, 1977: 72)

\footnotetext{
${ }^{3}$ Quando se refere o actor/cliente como decisor considera-se que este, apesar de conhecer as estratégias dos outros actores, tem poder institucional para ratificar uma decisão. No entanto, é de recordar que dificilmente o poder de decisão está num só actor, principalmente em processos de interesse público, o que significa que o decisor deve ser visto como o colectivo dos actores (Bana e Costa, 1993).
} 
No planeamento estratégico participativo o jogo estratégico dos actores, nomeadamente a relação entre o actor/cliente e os restantes actores deve basear-se na confiança, o que implica reduzir a zona de incerteza de todos os actores protagonistas deste processo, e não apenas do actor/cliente, o qual não deve ser considerado um "partenaire/adversaire".

Habitualmente, aquando da análise estratégica dos actores, a informação solicitada aos diferentes actores protagonistas do processo de planeamento, nomeadamente o conhecimento das suas estratégias, constrangimentos e potencialidades, a maior ou menor mobilização relativamente aos objectivos propostos, conflitualidades e meios de actuação, é controlada pelo actor/cliente, sendo a divulgação e discussão dos resultados totalmente gerida por este último.

Evidentemente que o actor/cliente, responsável pelo processo de acção, tem as suas próprias estratégias, que podem estar ou não em conflito com as de outros actores, mesmo que em determinados contextos, possa ser politicamente inoportuno assumir essas divergências e conflitualidades. Desta forma, pode considerar-se que os resultados de uma análise da estratégia de actores reforçam o poder do actor/cliente nesta relação de forças. Este utilizará estrategicamente essa informação, o que poderá mesmo passar pela sua não divulgação e discussão com os outros actores protagonistas do processo de planeamento ou censurar informação e divulgar apenas o que favorece os seus objectivos estratégicos!

No entanto, ao desencadear um processo de participação inerente a um plano estratégico exige-se credibilidade e transparência. Desta forma, há que assegurar que num processo de planeamento participativo existem condições para construir a democracia participativa e cumprir os "compromissos" assumidos, nomeadamente:

- comunicação e circulação de informação;

- discussão das várias estratégias, dos consensos e conflitos;

- e, divulgação dos resultados e opções estratégicas.

Se tal não se concretizar, os objectivos de participação e implicação dos actores poderão ficar comprometidos. Isabel Guerra alerta ainda para o moroso processo de construção de uma democracia participativa, que não se coaduna com a premência e necessidade do poder político em ter resultados, e "mostrar serviço":

"A clarificação de compromissos, a montagem de processo de acção e regulação colectiva é um jogo lento que se vai construindo pela acção, mas a urgência dos problemas práticos e a necessidade de 'mostrar serviço'frequentemente não se compadecem com este percurso de construção de uma democracia participativa. Estes processos vão, por vezes, gerando conflitualidades mal resolvidas que se manifestam nos momentos menos adequados e que vão perturbar as acções." (Guerra, 2000b: 54)

Se a construção do plano depende da referida coesão interna, que se vai construindo e consolidando, ao longo do processo, a já referida transparência deve ser assumida por todas as partes, e em particular pela entidade responsável e financiadora - o actor/cliente, o que pressupõe, como se referiu, a divulgação e discussão dos resultados da análise estratégica dos actores.

\section{O papel do investigador/cientista/analista na estratégia de actores}

Num processo de planeamento estratégico há que encontrar consensos, (construir consensos e não partir de consensos) face aos problemas e recursos identificados, bem como seleccionar as questões-chave face à mudança, daí o papel imprescindível dos actores sociais. Compete à equipa responsável pelo plano definir o papel e os recursos que serão necessários ao "actor público" para potenciar as oportunidades e contrariar as ameaças. Sem dúvida, que este último tem um papel primordial em todo o processo de desenvolvimento do plano.

Consoante a concepção de planeamento, assim se tem um papel diferenciado para o técnico de planeamento. No planeamento tradicional parte-se do pressuposto de que o técnico de planeamento tem uma posição neutra relativamente ao objecto de estudo, o que explica uma nítida distinção entre o técnico e o decisor enquanto político. Ou seja, o técnico é alguém com conhecimentos específicos mas sem qualquer implicação nas propostas de 
planeamento. Já no planeamento estratégico, a posição a assumir pelo especialista é a de um "agente de mudança", alguém que procura consensos entre os actores com estratégias diferentes, e nunca é considerado como um actor neutro. Isabel Guerra (2000b) chama a atenção para o seu papel de "actor animador" de consensos e de estratégias de mudança.

Tendo presente este papel interventor, numa análise de estratégia de actores integrada num processo de planeamento estratégico e participativo, com que dificuldade, limitações e exigências se confronta o técnico de planeamento?

$\mathrm{O}$ investigador/cientista/analista procura a partir das lógicas dos actores, das suas estratégias, consensos e conflitos, compreender as dinâmicas sociais. Nem sempre os resultados das estratégias dos actores são consensuais e favoráveis às expectativas do actor/cliente, podendo, por vezes, contrariar a prossecução dos seus objectivos estratégicos, há conflitos e constrangimentos que são explicitados e clarificados. Como tal, este "levantar do véu" é frequentemente incómodo para o actor/ /cliente, enquanto decisor/político, na medida em que uma das suas estratégias é ocultar todo o tipo de conflito, assim como evitar a revelação de quaisquer redes de poder (lobbies).

$\mathrm{O}$ actor/cliente tende a controlar o investigador/cientista/analista, não só tentando persuadi-lo a ter como interlocutores privilegiados os que considera favoráveis às suas políticas e como tal potenciais aliados, assim como na definição dos objectivos estratégicos para o território.

Ora, apesar de estar financeiramente dependente do actor/cliente, o investigador/cientista/analista deve ter autonomia e não estar comprometido com o actor/cliente, manter um certo distanciamento. Tem de ser uma entidade independente do actor/cliente, não sujeita a quaisquer tipo de pressões.

No entanto, o investigador/cientista/analista numa análise estratégica de actores, é também um actor, com uma determinada posição e uma estratégia face aos diversos actores envolvidos nesse jogo de poder. Desta forma, terá de ter as competências não só técnicas, mas também políticas, para interagir com os diferentes actores, negociar, tanto os consensos como as decisões. Tendo em conta a importância da dimensão política do conhecimento e o impacte político dos resultados de uma análise de estratégia de actores num processo de planeamento estratégico e participativo, cabe-lhe a "pesada" responsabilidade de criar condições para a acção colectiva, através da interacção prática e do sucesso (ou fracasso) dos projectos e acções comuns.

Ao considerar que o objectivo do investigador/ /cientista/analista é precisamente o de criar condições para a acção colectiva, e avaliando as pressões a que está sujeito ao longo desse processo, poder-se-ão enunciar alguns princípios deontológicos de actuação:

(a) Procura de uma certa racionalidade na ajuda à tomada de decisão;

(b) Assegurar a igualdade dos actores no acesso à informação;

(c) Autonomia e independência relativamente aos actores, e em particular do actor/cliente;

(d) Clareza nos pressupostos, na escolha dos métodos e na divulgação dos resultados;

(e) Defesa da natureza pública dos resultados, mais não seja para os actores envolvidos no processo;

(f) Contribuir para que a participação e implicação dos actores no processo de planeamento seja efectiva, e não apenas uma encenação ou uma afirmação ideológica, de defesa de uma democracia participativa.

No apoio à tomada de decisão, o investigador/ /cientista/analista parte de uma clarificação dos objectivos, consensos e conflitos dos diversos actores. Este percurso pode ser entendido como um processo de aprendizagem, dinâmico, onde se vão "afinando", "modelando" e consolidando as diversas estratégias e alianças, e que tem por objectivo reduzir o grau de incerteza quanto ao futuro.

Por outro lado, a igualdade dos actores face à informação, a autonomia e independência, e a defesa da natureza pública dos resultados, são para o investigador/cientista/analista uma questão deontológica, não se compadecendo com qualquer espécie de ingenuidade. Não poderá haver identificação com o actor/cliente relativamente aos outros actores protagonistas deste processo, nem cedências de qualquer tipo. Nomeadamente, a condução de todo o processo de investigação, a escolha dos actores que farão parte da análise, a recolha de informação e análise de resultados, assim como a circulação 
de informação, deve ser da exclusiva responsabilidade do investigador/cientista/analista e não deve existir qualquer tipo de interferências.

A implicação e participação de todos os actores no processo de planeamento, de uma forma efectiva e responsável, passam pela comunicação e, em particular, pela divulgação e discussão dos resultados da análise estratégica dos actores. Os diversos actores protagonistas do processo devem ser encarados não como sujeitos passivos, mas como quem procura utilizar o sistema para alcançar os seus próprios objectivos, o que implica a criação de condições que permitam a sua efectiva participação. Para tal, a constituição de um painel ou fórum de actores é um princípio e uma etapa fundamental de divulgação e discussão deste tipo de resultados.

A este propósito, Isabel Guerra (2000a: 101-102), entende a divulgação e discussão de resultados como uma necessidade técnica dos processos de desenvolvimento, não se tratando de obter

“(...) a participação mais ou menos folclórica da população nas actividades. Pretende-se, sobretudo, provocar uma tomada de consciência permanente do meio social sobre os seus próprios problemas e capacidade de solução. (...) este processo de 'participação' é não só uma questão ética, como ideológica, de defesa de uma democracia participativa - é antes de mais uma necessidade técnica dos processos de desenvolvimento. (...) A lógica colectiva dos processos de desenvolvimento, ao exigir o accionamento dos recursos (materiais mas também culturais e simbólicos) dos vários actores envolvidos, exige uma participação alargada para ser eficaz."

Como tal, exige-se que este actor clarifique os pré-requisitos e objectivos de uma análise de estratégia de actores, e que assegure o seu cumprimento e compromisso por parte do actor/cliente. De contrário, há o risco de os actores mobilizados e implicados neste "jogo", mas impedidos de participar na definição das opções estratégicas, se sentirem ludibriados e se considerarem alvo de um aproveitamento político, num processo para o qual parece não terem qualquer poder de decisão. Criam-se falsas expectativas e perde credibilidade e legitimidade o que caracteriza o planeamento participado e estratégico - a interactividade e participação.

\section{Conclusão}

Como se referiu, o planeamento estratégico tem como pressuposto a definição de opções estratégicas construídas a partir do interesse colectivo, o que se traduz pela mobilização e participação dos actores em todo o processo. No entanto, quanto maior a diversidade cultural e social dos vários actores, mais difícil se torna assegurar a sua participação e representatividade no processo de planeamento participativo. Contrariamente a actores maioritários ou com maior poder económico, é com grande esforço que os grupos mais desfavorecidos e mais vulneráveis socialmente conseguem ser representados no sistema político.

Como se enquadram e qual o possível envolvimento de actores com pouco, ou nenhum poder, no jogo estratégico de actores? Será que se está perante uma democracia participativa ou a sua legitimação e aparente defesa pelos poderes públicos, não é mais do que ideológica e politicamente correcta?

Impõe-se uma democracia participativa, não por uma questão ideológica, mas como uma exigência do próprio processo de planeamento: a efectivação do plano depende da implicação e contribuição voluntária dos actores.

"A renovação da teoria democrática assenta, antes de mais, na formulação de critérios de participação política que não confinem esta ao acto de votar. Implica, pois, uma articulação entre democracia representativa e democracia participativa." (Santos, 1994: 233)

O reconhecimento da especificidade e importância no planeamento participativo do actor/cliente e o investigador/cientista/analista, o que passa pela definição de regras claras e de uma deontologia do investigador/cientista/analista são essenciais para evitar o fracasso e a transformação de planeamento participativo em manipulação.

De certa forma, a informação e conhecimento detido pelos actores sociais, é uma forma de poder por parte destes, contrário aos interesses de um 
Estado centralizado e burocrático. Quanto maior a complexidade da realidade social, menor a capacidade de uma gestão centralizada e burocratizada, daí o interesse e necessidade por parte dos poderes públicos em investirem numa análise estratégica de actores. No entanto, o processo é contraditório na medida em que, se por um lado, as realidades sociais complexas exigem a participação dos diversos actores no processo de planeamento, por outro os poderes públicos encaram este envolvimento e participação dos diversos actores como uma ameaça pois representa precisamente a perca do poder centralizado e burocratizado, tendo como consequência um défice democrático.

Como se estabelece a fronteira entre a ciência e a política, entre conhecimento e acção? Boaventura Sousa Santos (2003:15), a propósito da necessidade de "reinventar a emancipação social", escreve:

"Estou convencido de que foi fatal para a ciência moderna e para as ciências sociais em especial ter abandonado o objectivo da luta por uma sociedade mais justa. Com isso estabeleceram-se barreiras entre a ciência e a política, entre conhecimento $e$ acção, entre a racionalidade e a vontade, entre a verdade e o bem que permitiram aos cientistas tornarem-se, com boa consciência, os mercenários dos poderes vigentes."

No contexto de uma democracia participada, Isabel Guerra (2006:159) considera que as perspectivas actuais exigem que o aumento do empowerment do cidadão, individual e/ou colectivamente considerado, está para além do conhecimento da dinâmica dos actores e da coordenação de parcerias, passa por acções que visem alterações da distribuição do poder e dos recursos.

"Infelizmente, o planeamento em Portugal tem ainda um cariz técnico, com pouca presença dos cidadãos que estão afastados dos centros de decisão, num processo onde se diluem as decisões e a personalização das relações de proximidade, afastadas em nome de um colectivo técnico ou político impessoal que não serve de interlocutor. As questões ligadas às formas de gestão participada, à co-partilha de decisões e à análise do impacte sobre a coesão social dos processos de planeamento são afastadas em nome de uma eficácia rudimentar. (...) a discricionariedade das formas de acção colectiva, a decisão ao sabor das circunstâncias, ou, pior ainda, dos jogos de poder tem como efeito frequente a demissão do Estado do seu verdadeiro papel e o seu posicionamento ao serviço dos interesses dominantes."

Efectivamente, a participação pode ser uma forma de controlo social organizado por parte de actores hegemónicos, contrariando sub-repticiamente qualquer tipo de negociação e mobilização de actores com menos capital político e económico, à partida fragilizados. Supostamente pertencem a este jogo, mas na realidade não têm qualquer poder de decisão; a participação torna-se um equívoco em todo este processo.

Tendo em conta a ambiguidade da participação associada a qualquer processo de planeamento estratégico e participativo, privilegia-se a importância da motivação pela participação:

- motivar e sensibilizar o actor-cliente para a importância de um planeamento participado, para o planeamento como um processo, o que implica ultrapassar eventuais défices de cultura democrática, garantindo nomeadamente a divulgação dos resultados;

- motivar os restantes actores para um processo de planeamento deste tipo, assegurando a sua efectiva participação e mobilização e a credibilidade de um planeamento estratégico e participado.

Dado o défice de participação dos diversos actores no processo de planeamento, é premente um debate público sobre as regras de participação, de deliberação e de distribuição de poder, o que passa por uma efectiva "democracia participativa de planeamento". 


\section{Bibliografia}

Bana e Costa, Carlos A., 1993, Processo de Apoio à Decisão: Problemáticas, Actores e Acções, Lisboa, CESUR/IST.

Crozier, Michel, e Erhard Friedberg, 1977, L'acteur et le système: les contraintes de l'action collective, Paris, Ed. Seuil.

Guerra, Isabel Carvalho, 2000a, Fundamentos e Processos de Uma Sociologia de Acção - O Planeamento em Ciências Sociais, Cascais, Principia.

Guerra, Isabel Carvalho, 2000b, "O planeamento estratégico das cidades. Organização do espaço e acção colectiva", Cidades - Comunidades e Territórios, 1, Dezembro.

Guerra, Isabel Carvalho, 2002, “Cidadania, exclusões e solidariedades. Paradoxos e sentidos das "novas políticas sociais", (colóquio Globalização. Fatalidade ou Utopia?), Revista Crítica de Ciências Sociais, 63, Dezembro, pp. 47-74.

Guerra, Isabel Carvalho, 2006, Participação e Acção Colectiva. Interesses, Conflitos e Consensos. Cascais, Principia.
Perestrelo, Margarida, 2005, Prospectiva: planeamento estratégico num contexto de desenvolvimento regional, Lisboa, Instituto Superior de Ciências do Trabalho e da Empresa, policopiado.

Santos, Boaventura de Sousa, 1994, Pela Mão de Alice. O Social e o político na pós-modernidade, Porto, Ed. Afrontamento.

Santos, Boaventura de Sousa (org.) et al., 2003, Democratizar a democracia: os caminhos da democracia participativa, Colecção Reinventar a Emancipação Social: Para Novos Manifestos/1, Porto, Ed. Afrontamento.

Simon, Herbert A., 1989, A Razão nas Coisas Humanas, Lisboa, Gradiva.

Simon, Herbert A., 1996, The Science of the Artificial, Massachusetts, Massachusetts Institute of Technology. 